\title{
Variable frequency control and filter design for optimum energy extraction from a $\mathrm{SiC}$ wind inverter
}

\author{
Abdallah Hussein, and Alberto Castellazzi \\ The University of Nottingham \\ Power Electronics, Machines and Control (PEMC) Group
}

\begin{abstract}
This paper proposes the optimised control and filter design of a $12 \mathrm{~kW}$ 3-phase 2-level wind inverter specifically taking into account the intermittent nature of the input power. In particular, the applied control scheme aims at optimising the low-load efficiency, which corresponds to the most frequent operational condition in time, by varying the switching frequency. Specifically, a silicon carbide ( $\mathrm{SiC}$ ) converter is addressed, which operates at relatively high frequency, thus enabling a significant reduction of the filter elements. So, the output filter design also needs to be optimised to ensure that the inverter electro-magnetic performance and the size reduction enabled by $\mathrm{SiC}$ are kept. That is achieved by designing a variable inductor based on soft saturation core material.
\end{abstract}

Index Terms-metaloxide semiconductor field-effect transistors (MOSFETs), two-level voltage source converter (2L-VSC), smallscale wind turbine, variable inductor, closed control loop.

\section{INTRODUCTION}

Wind power converters have to function under intrinsically intermittent input power availability conditions and, in particular, operate most of their lifetime at relatively low load conditions. So, it is important to optimise their design and behaviour taking the intermittent nature of the source into consideration. Power semiconductor devices based on $\mathrm{SiC}$ exhibit many advantages in industrial applications power electronics: higher switching frequency, higher temperature capability, higher power density and higher reliability [1]. Nowadays, the commercially available power MOSFETs that satisfy the above benefits are with voltage ratings of 400,650 , 900, 1200 and $1700 \mathrm{~V}$ for both discrete and module packages, and Schottky diodes with ratings up to $8 \mathrm{kV}$ [1]. This recent commercialization is expected to have the potential to deliver revolutionary impact on power electronics industry in the future. According to the availability of $\mathrm{SiC}$ power MOSFETs on the markets; the main areas that can be utilized by this technology are home appliances, switching power supply, PV inverters, speed drives, solid state transformers and small-scale wind turbines.

Most published studies have focused particularly on the benefits of $\mathrm{SiC}$ over $\mathrm{Si}$ in wind turbines [2]-[6], indicating the benefits to improve efficiency and higher switching frequency capability and higher power densities due to the heat-sink and inductor sizes reduction. However, in this study the aim at optimising the low load operation and energy efficiency rather than only the power efficiency taking advantage of the characteristics of $\mathrm{SiC}$ and the intermittent nature of wind power availability.
Small-scale wind turbines are mainly used to supply electricity to homes, farms, and small business in rural areas and developing countries. They differ from their large-scale wind turbine in their rating, size, generator type, and the topology of the power electronics conversion system [7]. For small-scale wind conversion system in the power ranges up to $100 \mathrm{~kW}$, it is a trend to use a PMSG in industry applications especially for a directly driven wind turbine with benefits of size and weight reduction. As there is no reactive power needed, the conversion system is a simple 3-phase diode rectifier with dcdc boost converter connected to 2-level 3-phase inverter as shown in Fig.1 [8], [9].

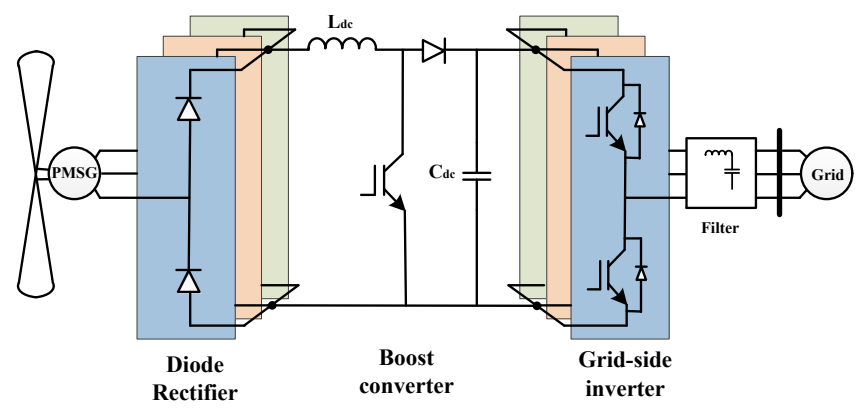

Fig. 1: Small scale wind turbine power conversion system.

The focus is on the inverter stage in this work, so that, the wind turbine model under the maximum power point tracking is simplified by a current source connected in parallel with the DC link capacitor of the grid-side inverter as shown in Fig. 2

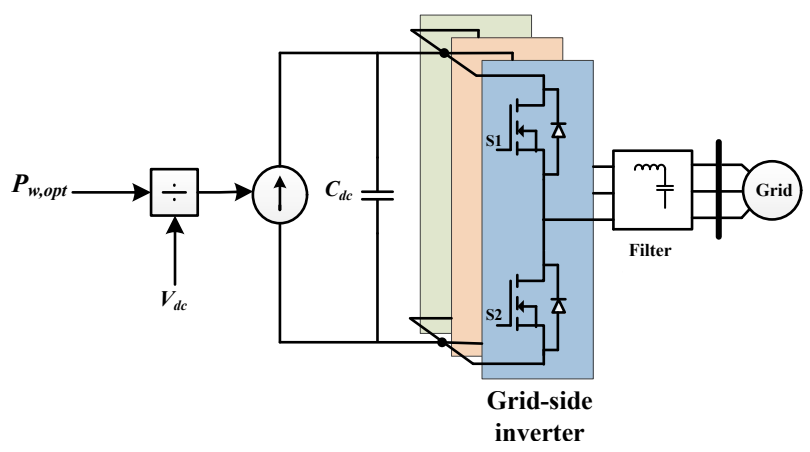

Fig. 2: Simplified model of small-scale wind turbine under MPPT.

The input signal of the current source is:

$$
I_{w}=\frac{P_{w, o p t}}{V_{d c}}
$$


Where, $P_{w, o p t}$ is the optimal wind turbine output power and $V_{d c}$ is the $D C$ link voltage of the converter.

A commercial wind turbine system and probability based on actual measured wind data are considered in this study. Fig.3 shows the output power curve of a $10 \mathrm{~kW}$ small-scale wind turbine, and the wind speed distribution versus wind speed. It is seen that wind turbines spend most of their operational time working at low output power (the region of interest).

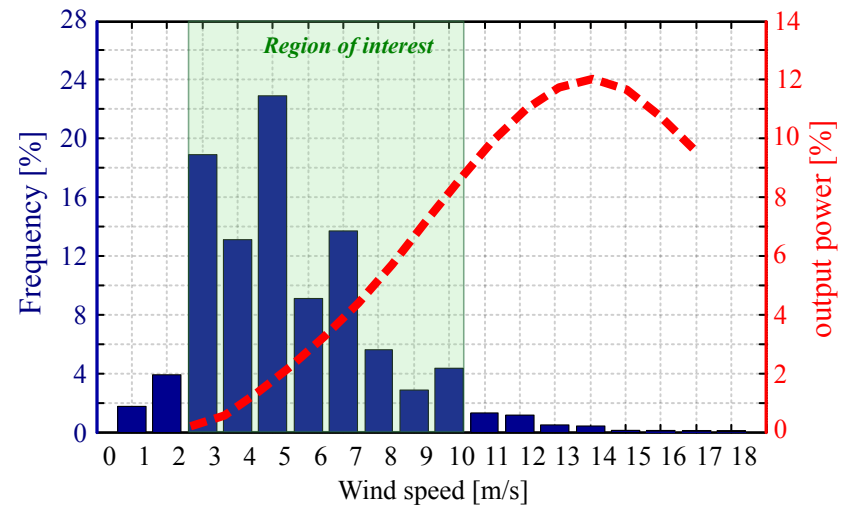

Fig. 3: The wind speed distribution (blue data) and wind output power (red data) versus wind speed.

\section{INVERTER EFFICIENCY AT DIFFERENT LOADS}

In this section, a SiC-based three-phase inverter has been designed and built in the lab to deliver a through characterization performance of $1200 \mathrm{~V} / 20 \mathrm{~A}$ SiC MOSFETs (CCS020M12CM2 from CREE). The inverter was $12 \mathrm{~kW} 3-$ phase 2-level used for small-scale wind turbines, and its parameters are shown in Table I. To deliver a demonstration of the inverter power cell characterization, a series of measurements of the power losses and efficiency are performed for different power loading upto $12 \mathrm{~kW}$ input power at heatsink temperature of $60^{\circ} \mathrm{C}$, which is a reference temperature for some industrial applications, and different switching frequency from $16 \mathrm{kHz}$ to $32 \mathrm{kHz}$. The dead-time of $500 \mathrm{~ns}$ and DC-link voltage of $720 \mathrm{~V}$ are considered. The test was made with a variable three-phase resistive load to emulate the grid connection at different power loading.

TABLE I: Converter parameters and test conditions

\begin{tabular}{cc}
\hline \hline Parameter & Value \\
\hline Input power rating, $P_{i n}$ & $12 \mathrm{~kW}$ \\
DC-link voltage, $V_{D C}$ & $720 \mathrm{~V}$ \\
DC-link capacitor $C_{D C}$ & $56 \mu \mathrm{F}$ \\
Grid phase voltage, $V_{g}$ & $230 \mathrm{~V}$ \\
Switching frequency, $f_{s w}$ & $16-32 \mathrm{kHz}$ \\
Dead-time & $500 \mathrm{~ns}$ \\
Devices & CREE CCS020M12CM2 \\
\hline
\end{tabular}

The test setup schematic is shown in Fig 4: the converter is powered by a dc power supply, and the power losses are measured by Yokogawa WT3000E precision power analyser. In this stage, to assess the performance of the power cell based on three-phase $\mathrm{SiC}$ power module, the voltage measurements are set before the filter inductor $\mathrm{L}_{f}$ to exclude the inductor losses from the assessment.
The DC-link PCB is designed based on planar structure to minimize parasitic inductance in the commutation loop at high switching speed, and two sets of DC link is to have a asymmetric parasitic inductance between the individual half-bridge sections. High frequency ceramic capacitors are fixed very close to inverter legs used to provide minimum voltage overshoots. The carrier and modulating signals are performed using a control platform based on Texas Instrument TMS320C6713 floating point digital signal processor (DSP) and Actel ProAsic3 field programmable gate array (FPGA), and then processed to the gate driver to generate the required switching sequence. The gate driver board is kept very close and directly connected to the power cell in order to minimize the driving loop and reduce the noise pick-up at the gate signals.

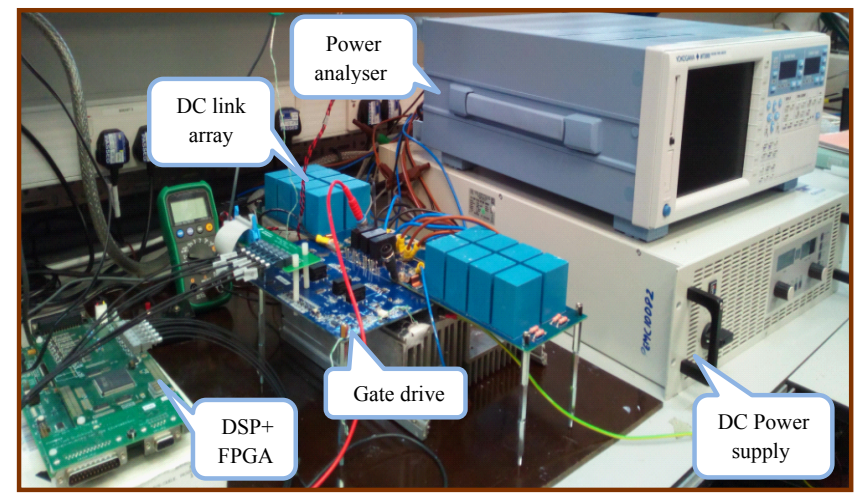

Fig. 4: Three-phase Inverter test setup.

The power cell measured efficiency against the output power at different switching frequency and at $60^{\circ} \mathrm{C}$ heat sink temperature, is shown in Fig. 5. At higher output powers, the performance difference between different switching frequencies is insignificant, it is clear by increasing the switching frequency by a factor 2 implies a reduction in efficiency of less than $0.35 \%$ when working around $11.5 \mathrm{~kW}$ output power and $60^{\circ} \mathrm{C}$ heat sink temperature (less than $40 \mathrm{~W}$ difference in total power dissipation). At light loads (the region of interest), in which the wind turbines spend most of their operational time, however, the efficiency is reduced gradually by increasing the switching frequency. The reason for the efficiency reduction is due to the domination of switching losses instead of conduction losses. For example, at $400 \mathrm{~W}$ output power which corresponds to the starting wind speed, about 5\% efficiency drop in the performance curve is observed when moving from $16 \mathrm{kHz}$ to $32 \mathrm{kHz}$ switching frequencies.

Fig. 6 presents the annual lost energy calculated based on the experimental measured power losses of the converter power cell at different power loading and the hourly wind speed distribution throughout the year in Nottingham. It is clear that lost energy difference at high wind speeds, which has a chance of small fraction of wind turbine operational time, is almost negligible. The significant reduction of efficiency at lighter loads in the region of highly probable wind speed distribution, on the other hand, leads to a significant difference in the lost energy throughout the whole year. To minimize the lost energy at partial loads, one can consider the reduction of 


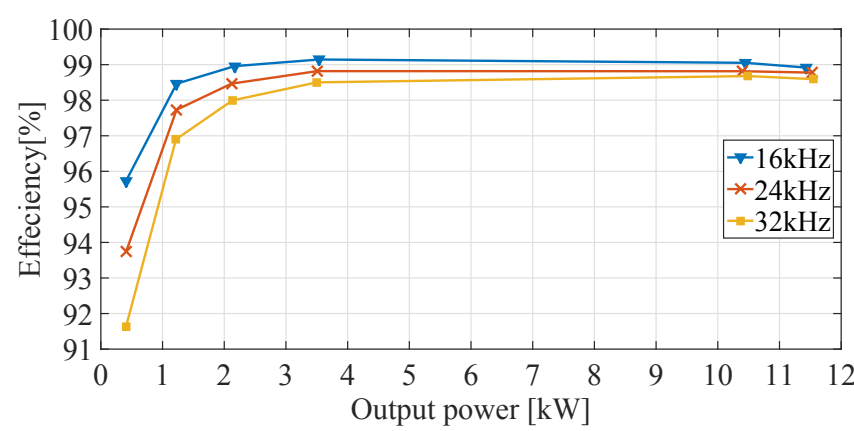

Fig. 5: Power cell measured efficiency vs. output power.

the lost energy by changing the switching frequency in the region of light loading.

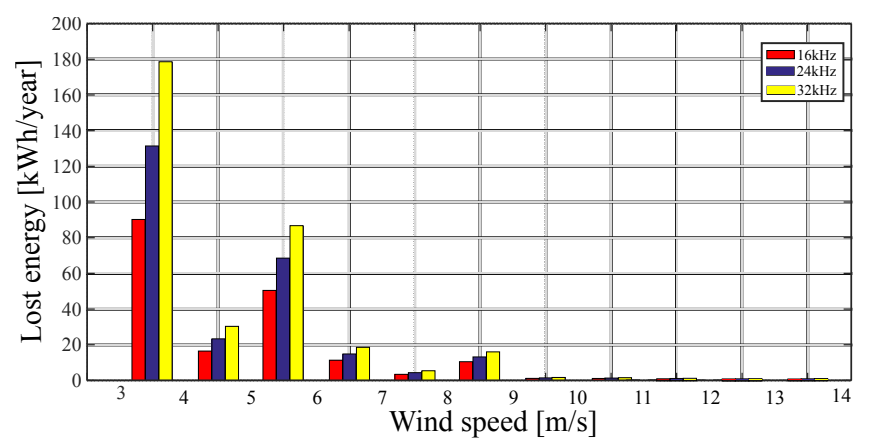

Fig. 6: Annual lost energy vs. wind speeds at different switching frequencies.

\section{DESIGN OF VARIABLE FREQUENCY CONTROL}

To improve the converter efficiency over a wide range of operation, one important parameter is the switching frequency. The switching frequency is varied by tracking the peak load current based on the relation shown in Fig.7, which is extracted based on the filter-inductor requirement to ensure the harmonic distortion limits and the nature of wind speed distribution. This relation is implemented in a C script in DSP of the control platform to drive the operating switching frequency. Fig.8 shows an implementation flow chart for the variable switching frequency algorithm. The algorithm can be run continuously, the sensed input current are taken from the Analog-to-Digital Converter(ADC). Next, the algorithm replaces the previous sample of the current with the present sample, and averages the number of samples per cycle to generate the rms and peak current. Based on the current value, the switching frequency $\left(f_{s w}[k H z]\right)$ will updated.

$$
f_{s w}= \begin{cases}16, & 1 A \leq I \leq 8 A \\ 0.003 I^{2}+0.002 I+13.86, & 8 A<I \leq 17.5 A \\ 32, & 17.5 A<I \leq 24.5 A\end{cases}
$$

\section{DESIGN OF VARIABLE INDUCTOR-FILTER}

The minimum inductance value of the inductor-filter for various frequencies, i.e $16 \mathrm{kHz}$ to $32 \mathrm{kHz}$, are calculated based on

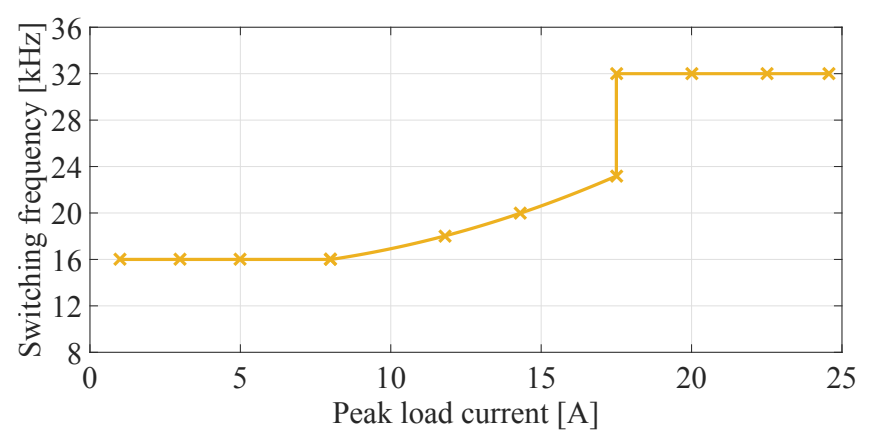

Fig. 7: Switching frequency and output current relationship implemented in the control platform.

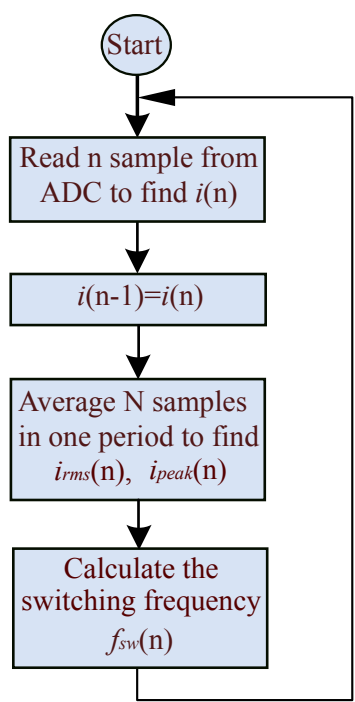

Fig. 8: Variable switching frequency control algorithm flowchart.

(2) [10], taken into account the maximum output ripple current of $20 \%$ of the peak current [11]. The switching frequencies and the corresponding minimum required inductance are listed in Table II.

$$
L_{f(\min )}=\frac{V_{d c}}{4 f_{s w} \triangle I_{P P}}
$$

TABLE II

\begin{tabular}{cc}
\hline \hline$f_{s}(k H z)$ & $L_{\min }(\mathrm{mH})$ \\
\hline 16 & 2.3 \\
24 & 1.5 \\
32 & 1.1
\end{tabular}

Here, we investigate the use of Kool $\mathrm{M} \mu$ core material for the design of variable inductor with $\mathrm{SiC}$ switches operating at variable switching frequency, i.e $16 \mathrm{kHz}$ to $32 \mathrm{kHz}$. This material has a soft saturation behaviour: it permits lower permeability at high currents, while higher permeability values at low currents. However, inductors designed using ferrite cores exhibit constant permeability over the dc bias current range and the permeability sharply dropped when the core operating close to saturation as shown in Fig.9. 


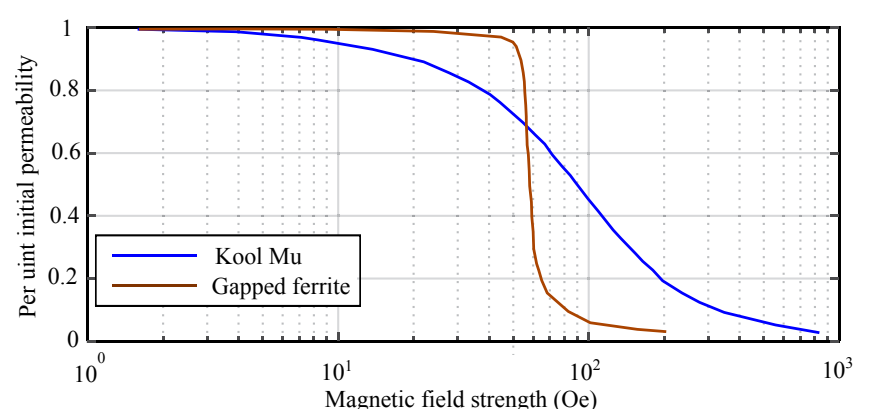

Fig. 9: The permeability of $60 \mu$ Kool $\mathrm{M} \mu$ powdered iron core and gapped ferrite core versus magnetic field strength.

The material properties of the Kool M $\mu$ LE114 E-core are mentioned in [12]. It has a permeance of 445 for $60 \mu \operatorname{KoolM} \mu$ and a relative permeability of 60 at no load and characterized by a distributed air gap which has no issues with the fringing flux.

Three single-phase Kool $\mathrm{M} \mu$ inductors were designed with 85 turns using $11 \times 0.63 \mathrm{~mm}$ round conductor resulting in $1.1 \mathrm{mH}$ inductance at the maximum current of $24.5 \mathrm{~A}$ and switch frequency of $32 \mathrm{kHz}$. Some design simulations are performed to calculate the variable inductance value at different dc offset currents as shown in Table III, where the inductance value is $2.97 \mathrm{mH}$ at $1 \mathrm{~A}$ current which reduces to $1.07 \mathrm{mH}$ at 25A.

TABLE III

\begin{tabular}{cccc}
\hline \hline$\% \mu_{r}$ & $\mu_{r}$ & $I(A)$ & $L(m H)$ \\
\hline 100 & 60 & 1 & 2.97 \\
85 & 51 & 5.7 & 2.73 \\
70 & 42 & 11 & 2.25 \\
55 & 33 & 15.9 & 1.77 \\
35 & 21 & 25 & 1.07 \\
& & & \\
\hline
\end{tabular}

The designed single-phase $60 \mu$ Kool $\mathrm{M} \mu$ inductor was tested by impedance spectroscopy up to $20 \mathrm{~A}$ dc bias current (the current limit of the impedance analyser). The calculated results are in agreement with measurements over the dc offset current range as shown in Fig. 10.

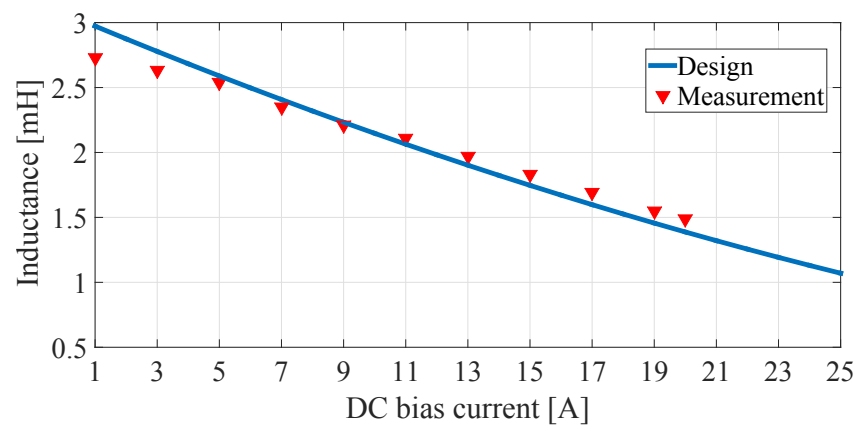

Fig. 10: Calculated variable inductance and measured values vs. dc offset current

\section{EXPERIMENTAL VERIFICATION}

The three-phase two-level inverter with the technical parameters given in Table I will be used with the variable inductor for the verification of the variable switching frequency technique at low power demands. The final design of variable inductorfilter together with the variable inductor are shown in Fig. 11.

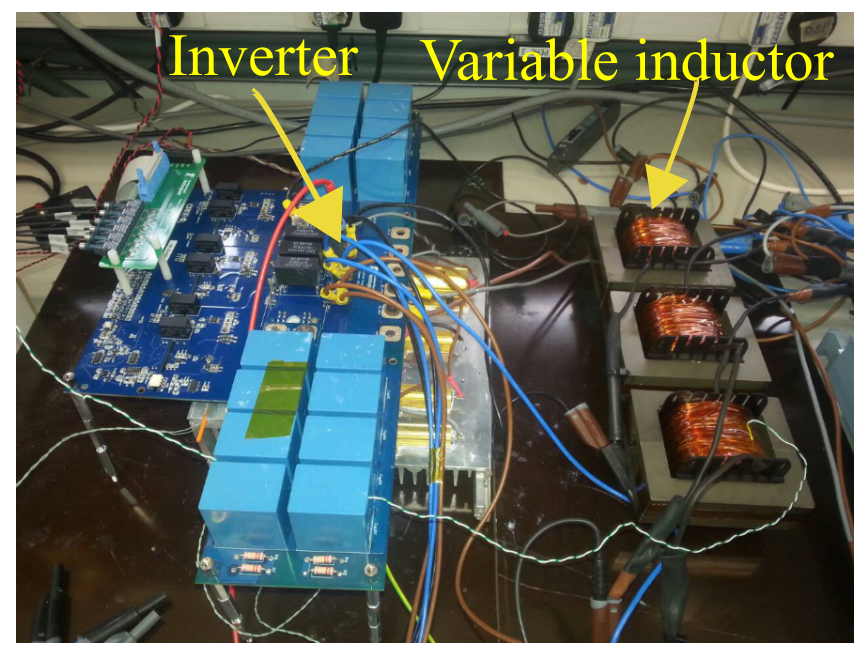

Fig. 11: Hardware of variable inductor-filter with 3-phase 2-level inverter.

Fig 12 shows the experimental phase current waveform at full load: the current is processed in the fast fourier transform (FFT) and its spectrum is shown in Fig. 13 and Fig. 14, which indicates that the total harmonic distortion (THD), which is less than 5\%, and the first 40th current harmonics orders meet the standard requirements [13], [14].

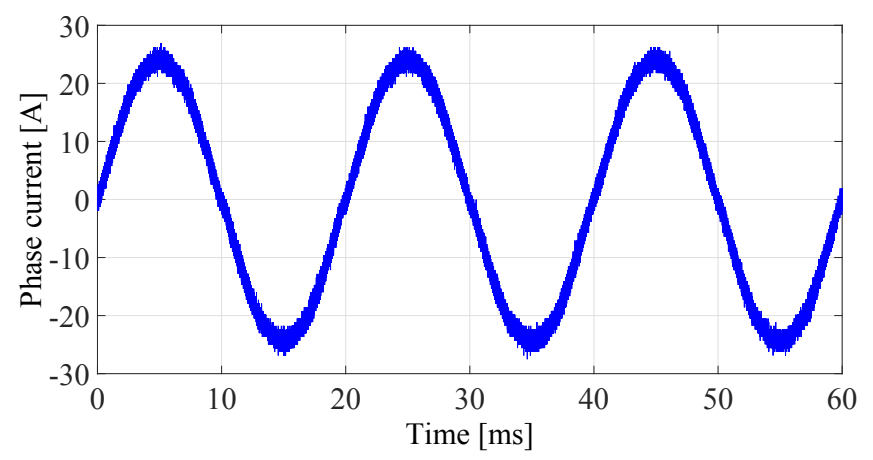

Fig. 12: Experimental current waveform of the inverter at full power.

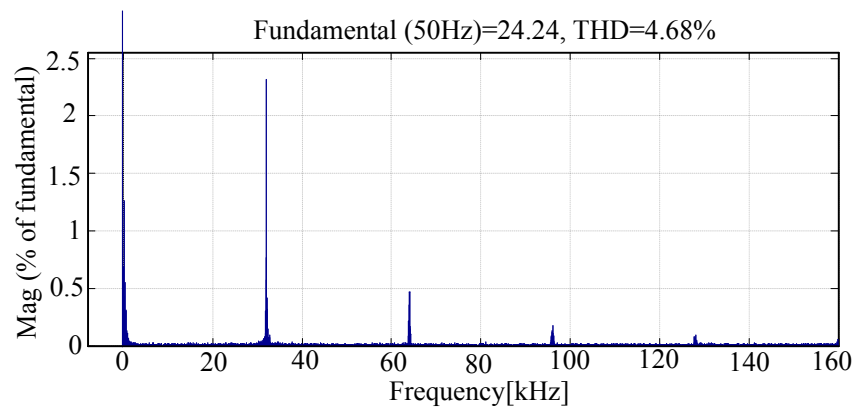

Fig. 13: Current spectrum at full power.

The design also ensures that the power quality requirements is attained over the whole range of wind turbine power loading. 


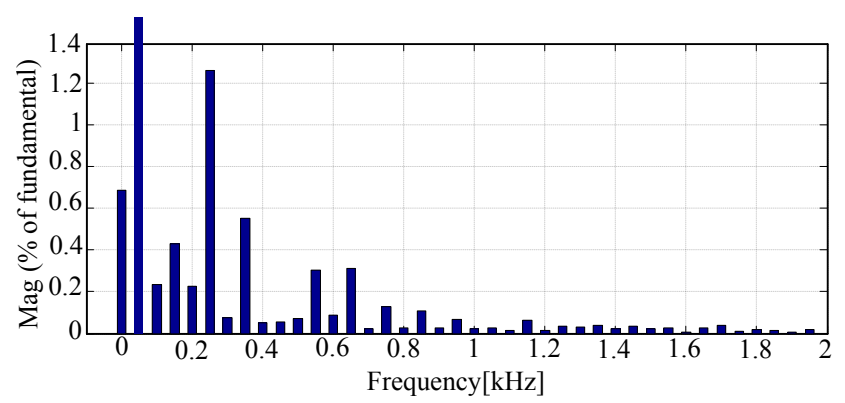

Fig. 14: Current harmonic limits for the first $40^{\text {th }}$ harmonics at full power.

The total demand distortion (TDD) gives better insight about the impact of harmonic distortion at different loads, i.e the THD could be very high at low loads, but its impact on the system is low. Fig 15 shows the TDD is comply with the grid requirements, which is less than 5\% [13] over the whole range of loading even at high THD at low power demands.

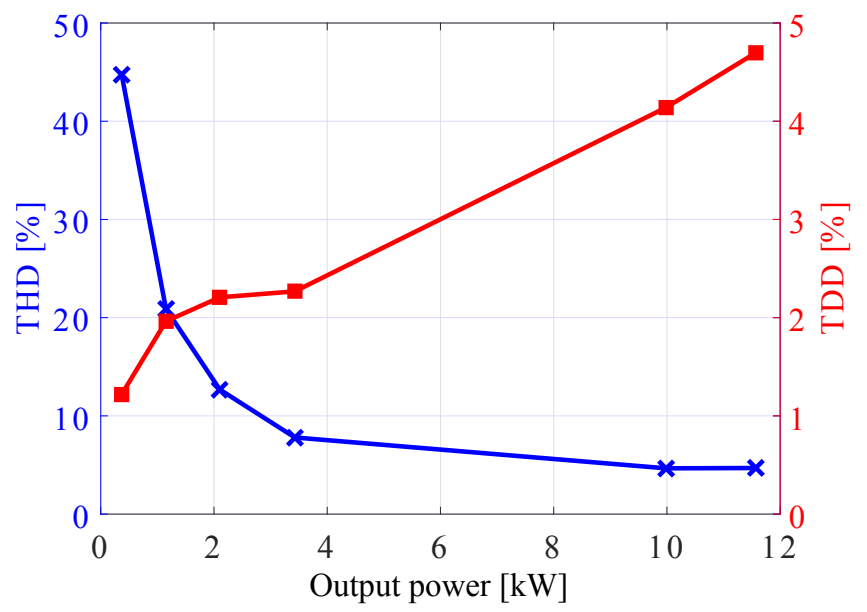

Fig. 15: Measured current THD and TDD for various output power.

Yokogawa WT3000E precision power analyser is used to measure the overall efficiency. The voltage output is measured after the filter-inductor to include the inductor losses together with the power cell losses. The gate driver and the control signal losses are excluded from the measurements. The overall efficiency with fixed switching frequency $(32 \mathrm{kHz})$ and variable switching frequency $(16 \mathrm{kHz}-32 \mathrm{kHz})$ is presented in Fig. 16. The performance difference between fixed and variable switching frequency becomes clearer at low power demand, which corresponds to the most frequent operational time of wind turbine. The converter achieved peak efficiency of $99 \%$ with variable switching frequency.

For grid-connected applications, the annual cumulative lost energy for $\mathrm{SiC}$ inverter with fixing switching frequency is about $227.5 \mathrm{kWh}$, and in contrast, $111.2 \mathrm{kWh}$ for inverter with variable switching frequency as shown in Fig 17. This results in a total lost energy saving up-to $51 \%$ by adapting variable switching frequency concept.

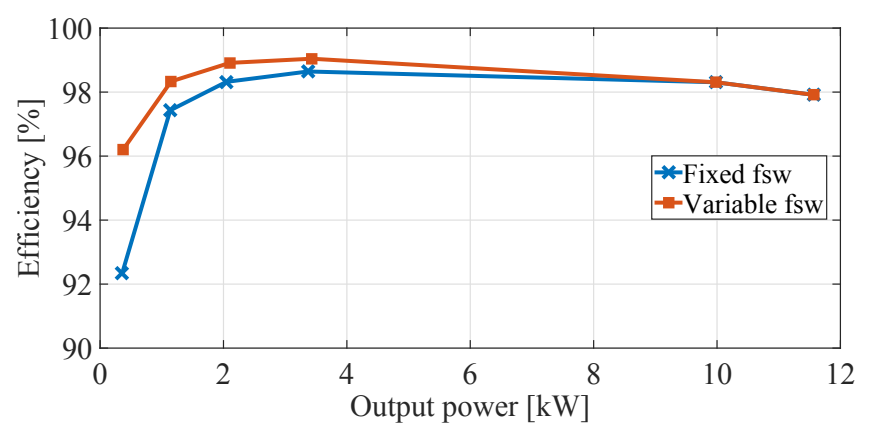

Fig. 16: Measured overall efficiency vs. Load operating at fixed and variable switching frequency.

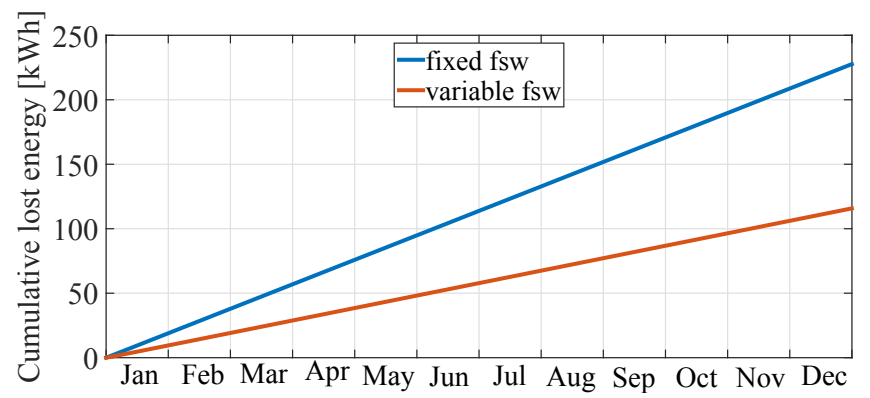

Fig. 17: Cumulative energy loss of the two-level grid-connected inverter based on fixed and variable switching frequency.

\section{CONCLUSIONS}

Given the fact that wind turbines work at their low output power for most of their operational time, the authors have presented an approach to maximize the converter efficiency by varying the switching frequency at the region of highly probable wind speed distribution. This corresponding to an increase in the annual energy delivered to the grid (about $51 \%$ saving in the lost energy), while keeping the decrease in the size of passive filter elements due to high frequency capability of SiC MOSFETs. Finally, the electro-magnetic performance of the inverter was experimentally demonstrated, meeting grid quality requirements at full and partial loads.

\section{REFERENCES}

[1] A. Castellazzi, A. Fayyaz, G. Romano, L. Yang, M. Riccio, and A. Irace, "Sic power mosfets performance, robustness and technology maturity," Microelectronics Reliability, vol. 58, pp. 164-176, 2016.

[2] H. Zhang and L. M. Tolbert, "Efficiency impact of silicon carbide power electronics for modern wind turbine full scale frequency converter," IEEE Transactions on Industrial Electronics, vol. 58, no. 1, pp. 21-28, Jan 2011.

[3] M. Adamowicz, S. Giziewski, J. Pietryka, M. Rutkowski, and Z. Krzeminski, "Evaluation of sic jfets and sic schottky diodes for wind generation systems," in 2011 IEEE International Symposium on Industrial Electronics, June 2011, pp. 269-276.

[4] W. L. Erdman, J. Keller, D. Grider, and E. VanBrunt, "A 2.3-mw medium-voltage, three-level wind energy inverter applying a unique bus structure and 4.5-kv si/sic hybrid isolated power modules," in 2015 IEEE Applied Power Electronics Conference and Exposition (APEC), March 2015, pp. 1282-1289.

[5] A. Blinov, A. Chub, D. Vinnikov, and T. Rang, "Feasibility study of si and sic mosfets in high-gain dc/dc converter for renewable energy applications," in IECON 2013 - 39th Annual Conference of the IEEE Industrial Electronics Society, Nov 2013, pp. 5975-5978.

[6] A. Hussein, A. Castellazzi, P. Wheeler, and C. Klumpner, "Performance benchmark of si igbts vs. sic mosfets in small-scale wind energy conversion systems," in 2016 IEEE International Power Electronics and Motion Control Conference (PEMC), Sept 2016, pp. 963-968. 
[7] D. M. Whaley, G. Ertasgin, W. L. Soong, N. Ertugrul, J. Darbyshire, H. Dehbonei, and C. V. Nayar, "Investigation of a low-cost gridconnected inverter for small-scale wind turbines based on a constantcurrent source pm generator," in IECON 2006 - 32nd Annual Conference on IEEE Industrial Electronics, Nov 2006, pp. 4297-4302.

[8] F. Blaabjerg, M. Liserre, and K. Ma, "Power electronics converters for wind turbine systems," IEEE Transactions on Industry Applications, vol. 48, no. 2, pp. 708-719, March 2012.

[9] M. Malinowski, A. Milczarek, R. Kot, Z. Goryca, and J. T. Szuster, "Optimized energy-conversion systems for small wind turbines: Renewable energy sources in modern distributed power generation systems," IEEE Power Electronics Magazine, vol. 2, no. 3, pp. 16-30, Sept 2015.

[10] Y. Liu, H. A. Mantooth, J. C. Balda, and C. Farnell, "Realization of high-current variable ac filter inductors using silicon iron powder magnetic core," in 2017 IEEE Applied Power Electronics Conference and Exposition (APEC), March 2017, pp. 855-860.

[11] T. C. Y. Wang, Z. Ye, G. Sinha, and X. Yuan, "Output filter design for a grid-interconnected three-phase inverter," in Power Electronics Specialist Conference, 2003. PESC '03. 2003 IEEE 34th Annual, vol. 2, June 2003, pp. $779-784$ vol.2.

[12] P. P. U. . Magnetics Powder Core Catalog, MAGNETICS.

[13] "Ieee recommended practice and requirements for harmonic control in electric power systems - redline," IEEE Std 519-2014 (Revision of IEEE Std 519-1992) - Redline, pp. 1-213, June 2014

[14] "Photovoltaic (pv) systems characteristics of the utility interface," International Advances in Surgical Oncology Electrotechnical Commission, Geneva, Switzerland, IEC 61727, 2004. 